\title{
Are enteric infections sexually transmitted in British Columbia?
}

\author{
Narayan $\mathrm{S}^{1 *}$, Galanis $\mathrm{E}^{2}$, BC STEl Group ${ }^{3}$
}

\begin{abstract}
Background: Enteric infections may on occasion be sexually transmitted, particularly among people who engage in oral-anal sexual contact. Although outbreaks of enteric infections have been reported among men who have sex with men (MSM) in British Columbia (BC), the epidemiology of sexually transmitted enteric infections has never been assessed.
\end{abstract}

Objective: To describe the epidemiology of enteric infections in $B C$ to determine if sexual transmission may be occurring.

Methods: A descriptive analysis was conducted of all reported cases of shigellosis, amebiasis and giardiasis in BC for the period 2003-2012.

Results: For shigellosis and amebiasis, there was a high male-to-female ratio and a higher rate of infection in males aged 20-59 years as compared to all other age-sex groups. Additionally, for shigellosis, adult males were significantly more likely than females to acquire disease locally (RR 1.9; Cl 1.7--.4).

Conclusion: Analysis suggests that sexual transmission of enteric infections, particularly shigellosis and amebiasis, may be occurring in MSM in BC. Further studies are indicated.

Suggested citation: Narayan S, Galanis E. BC STEI Group. Are enteric infections sexually transmitted in British Columbia? Can Comm Dis Rep 2016; 42-2:24-29. https://doi.org/10.14745/ccdr.v42i02a01

\author{
Affiliations \\ ${ }^{1}$ Simon Fraser University, Burnaby, \\ $\mathrm{BC}$ \\ ${ }^{2} \mathrm{BC}$ Centre for Disease Control, \\ Vancouver, BC \\ ${ }^{3} \mathrm{BC}$ STEl group membership: \\ Forsting $\mathrm{S}^{4}$, Hoang $\mathrm{L}^{2}$, Jeyes $\mathrm{J}^{5}$, \\ Nowakowski $\mathrm{C}^{6}$, Ritson $\mathrm{M}^{4}$, Stone \\ $\mathrm{J}^{7}$, Tone $\mathrm{G}^{8}$. \\ ${ }^{4}$ Vancouver Coastal Health, \\ Vancouver, BC \\ ${ }^{5}$ Interior Health Authority, \\ Kelowna, BC \\ ${ }^{6}$ Vancouver Island Health \\ Authority, Victoria, BC \\ ${ }^{7}$ Fraser Health Authority, Surrey, \\ BC \\ ${ }^{8}$ First Nations Health Authority, \\ Prince George, BC
}

*Correspondence: sanaraya@ sfu.ca

\section{Introduction}

Enteric pathogens are most commonly transmitted through consumption of contaminated food or water (1-3). However, some enteric pathogens can also be transmitted through sexual practices involving fecal-oral contact, such as oral-anal, oral-genital and anal-genital intercourse (4-6). Although these sexually-transmitted enteric infections (STEIs) can occur in heterosexual individuals who engage in unprotected anal sexual contact, they are more common in men who have sex with men (MSM) than any other adult populations $(4,5,7-9)$.

Pathogens transmitted sexually include Entamoeba histolytica, Giardia lamblia, Shigella (3,5,7,10-12), Salmonella (13) and Campylobacter (14). However, Entamoeba histolytica, Giardia lamblia and Shigella are most commonly STEls $(8,15,16)$. Inadvertent ingestion of minute amounts of feces containing as few as 10-100 organisms of Shigella bacteria, Entamoeba histolytica or Giardia lamblia cysts, during oral-anal sexual contacts could deliver a sufficient dose to cause infection. This low infectious dose also explains the tendency of these three pathogens to easily spread from person-to-person $(7,17,18)$.
The incubation period for shigellosis is short; one to two days. It is characterized by diarrhea (which may be bloody and contain pus), fever and tenesmus, and is usually a self-limiting infection (12). Although $90 \%$ of Entamoeba histolytica infections are asymptomatic, fever, diarrhea and abdominal cramps can occur two to four weeks after exposure to the parasites. The infection resolves with treatment in two weeks (12). Giardiasis is usually asymptomatic in humans but may produce low-grade fever, foul-smelling diarrhea and abdominal cramps and bloating, one to two weeks after exposure. Symptoms usually last one to three weeks and people with healthy immune systems normally clear the infection on their own. Treatment may be required for immunocompromised patients $(12,19)$.

Shigellosis, amebiasis and giardiasis are reportable communicable disease in British Columbia (BC). While past reports have highlighted outbreaks of shigellosis among the MSM population in BC $(20,21,22)$, the epidemiology of STEls, including shigellosis, has never been assessed in BC and is therefore not well understood. The objective of this study was to describe the epidemiology of these three infections in $B C$ to determine if sexual transmission may be occurring and to identify the population and regions at risk of STEI. 


\section{Methods}

A retrospective descriptive analysis was conducted of shigellosis, amebiasis and giardiasis cases reported in BC for the period 2003-2012. All cases were laboratory-confirmed and identified from the Integrated Public Health Information System (iPHIS). Exposure information including sexual activity and travel history was reviewed for all cases. Travel information was obtained from the Primary Access Regional Information Systems (PARIS) for Vancouver Coastal Health Authority cases and from iPHIS for the remaining health authorities. Travel information was classified as either "international travel" (if travel outside of Canada was reported within four days of symptom onset) or "local" (if the case reported no travel, or travel within Canada, within $\mathrm{BC}$, or within the health authority of residence) (23). Exposure information was available only for shigellosis and amebiasis as giardiasis cases are not routinely followed-up by public health authorities in BC. Information on outbreaks was obtained from the Canadian Network for Public Health Intelligence outbreak summary module, BC Centre for Disease Control outbreak investigation reports and discussion with experts.
Statistical analyses included case counts and incidence rates (IR) by year, geography, sex and age groups. Population estimates for IR calculation were obtained from BC Stats

(available at: http://www.bcstats.gov.bc.ca). Cases were grouped into one of four age groups. The 20-59 year age group represented the sexually active population because it was appeared to have an excess number of adult male cases in the preliminary analysis.

Data were analyzed using Microsoft Excel® 2007 and OpenEpi software (version 2.3.1). Chi square tests were used to compare proportions of shigellosis cases associated with international travel to that of local cases. A $p$ - value of $<0.05$ was considered to be significant. Relative risk with $95 \%$ confidence intervals was calculated to compare the risk of shigellosis in these two groups.

Table 1: Characteristics and incidence rates (IR) per 100,000 population for reported cases of giardiasis, amebiasis and shigellosis in British Columbia, 2003-2012

\begin{tabular}{|c|c|c|c|}
\hline Characteristics & $\begin{array}{l}\text { Giardiasis } \\
\text { (IR[number]) }\end{array}$ & $\begin{array}{l}\text { Amebiasis } \\
\text { (IR[number]) }\end{array}$ & $\begin{array}{l}\text { Shigellosis } \\
\text { (IR[number]) }\end{array}$ \\
\hline Provincial average annual IR & $15.2(6,593)$ & $7.7(3,359)$ & $4.6(1,986)$ \\
\hline \multicolumn{4}{|l|}{$\operatorname{Sex}^{1}$} \\
\hline Female & $12.1(2,648)$ & $4.2(928)$ & $3.7(806)$ \\
\hline Male & $18.3(3,933)$ & $11.2(2,422)$ & $5.5(1,176)$ \\
\hline Male : female & $1.5: 1$ & $2.6: 1$ & $1.5: 1$ \\
\hline \multicolumn{4}{|l|}{ Age group (males + females) } \\
\hline 0 to 9 years & $26.9(1,184)$ & 4.1 (159) & $4.8(200)$ \\
\hline 10 to 19 years & $10.0(534)$ & 3.9 (189) & $2.5(131)$ \\
\hline 20 to 59 years & $16.6(4,177)$ & $11.2(2,542)$ & $5.9(1,393)$ \\
\hline $60+$ years & 7.9 (698) & $6.1(469)$ & $3.2(262)$ \\
\hline \multicolumn{4}{|l|}{ Health authority } \\
\hline Fraser Health Authority & $16.4(2,496)$ & $7.8(1,199)$ & $4.6(705)$ \\
\hline Interior Health Authority & $10.7(757)$ & $1.2(89)$ & $1.8(127)$ \\
\hline Northern Health Authority & $9.8(279)$ & $0.2(5)$ & $1.2(34)$ \\
\hline Vancouver Coastal Health Authority & $20.4(2,225)$ & $16.2(1,768)$ & $8.2(894)$ \\
\hline Island Health Authority & $11.4(836)$ & $4.0(298)$ & $3.1(226)$ \\
\hline \multicolumn{4}{|l|}{ Age group $20-59$ years $^{1}$} \\
\hline Female & $12.6(1,592)$ & $5.6(630)$ & $4.6(541)$ \\
\hline Male & $20.6(2,578)$ & $16.7(1,905)$ & $7.3(848)$ \\
\hline Male-to-female ratio & 1.6:1 & 3.0:1 & 1.6:1 \\
\hline
\end{tabular}

\footnotetext{
1 Two transgendered cases not included
} 
Figure 1: Distribution of shigellosis cases by age category and sex for British Columiba, 2003-2012

Distribution of shigellosis cases by age category and sex for BC, 2003-2012

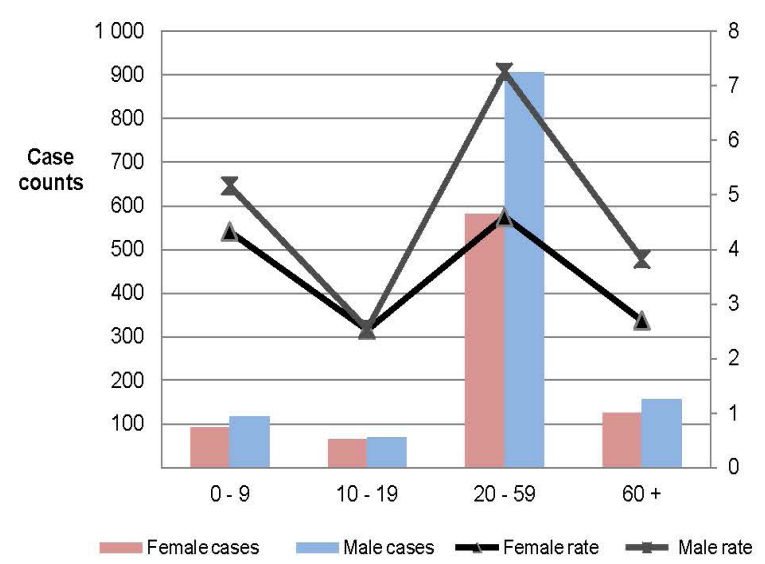

\section{Results}

Overall, Vancouver Coastal Health Authority reported the highest average annual IR for all three infections, followed by Fraser Health Authority, Island Health Authority, Interior Health Authority and Northern Health Authority (Table 1). A higher male-to-female ratio was observed for all three infections in all health authorities; however, the majority of shigellosis and amebiasis was reported in those 20-59 years of age (5.9 and 11.2 per 100,000 population) and for giardiasis in children aged 0-9 years (26.9 per 100,000 population).

The average annual IR for shigellosis was 4.6 per 100,000 population (Table 1). The annual IR fluctuated with peak rates seen in 2003, 2005 and 2007. A declining rate was observed, from 6.3 in 2007 to 3.8 per 100,000 population in 2012 (data not shown). Overall, rates were higher in males than females (male-to-female ratio of 1.5:1), with highest IR among males aged $20-59$ years (7.3 per 100,000 population)

(Figure 1). Vancouver health services delivery area reported the highest average annual rate at 11.2 per 100,000 population (Figure 2).

Four shigellosis outbreaks were reported during 2003-2012. The first two outbreaks were caused by Shigella sonnei in 2007 and occurred in the Vancouver health services delivery area and Fraser Health Regions. The first outbreak occurred in the early part of 2007 and affected the MSM population and the second outbreak due to a different Shigella sonnei strain occurred in the latter part of 2007 and affected the homeless population (22). A third outbreak of Shigella sonnei linked to a local restaurant occurred in 2010 in the Okanagan health service delivery area (20). The final outbreak, due to Shigella flexneri, occurred during 2008-2012 and affected the MSM population in Vancouver health service delivery area (20).

Shigella sonnei (56.4\%) was the most common strain reported in BC during 2003-2012, followed by Shigella flexneri (35.7\%), Shigella boydii (5.1\%) and Shigella dysenteriae (2.8\%). Analysis
Figure 2: Shigellosis average annual incidence rate by health service delivery area in British Columbia, 2003-2012

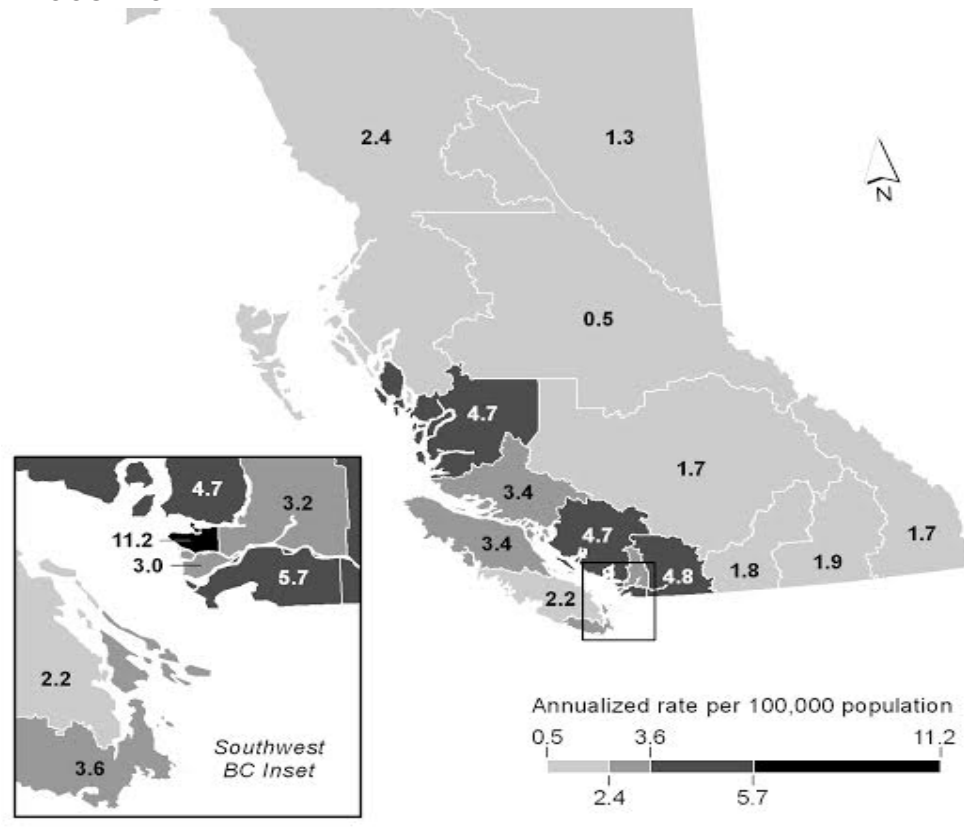

demonstrated a shift in the dominating Shigella strain: during 2003-2008, Shigella sonnei was the prevalent infecting species (65.0\%) in BC and during 2009-2012, Shigella flexneri was the prevalent infecting species (52.1\%).

Limited exposure information was documented. In total, $58.0 \%$ of shigellosis cases, $15.1 \%$ of giardiasis cases and $8.3 \%$ of amebiasis cases had exposure information entered in iPHIS. Of these, less than $1 \%$ mentioned sexual activity as an exposure. During 2008-2012, 928 shigellosis cases were reported to PARIS and iPHIS, 654 cases (70.5\%) of these had travel information documented, and 461 cases (70.4\%) reported international travel. Overall, males were at a greater risk of acquiring shigellosis locally compared to females (RR 1.6; Cl 1.4-1.8). Among the 20-59 year age group, males were at greater risk of acquiring shigellosis locally compared to females (RR 1.9; Cl 1.7-2.4).

The average annual IR of amebiasis in BC was 7.7 per 100,000 populations (Table 1). Rates were higher in males than females across all age groups (male-to-female ratio of 2.6:1); with highest IR among males aged 20-59 years (16.7 per 100,000 population). Vancouver Coastal Health Authority reported the highest rate (16.2 per 100,000 population). No outbreaks were reported during the study period.

The average annual IR of giardiasis in BC was 15.2 per 100,000 population (Table 1). Vancouver Coastal Health Authority reported the highest average annual IR (20.4 per 100,000 population). The IR was higher in males than females across all age groups (male:female ratio of 1.5:1), with the highest IR observed in males aged $0-9$ years (28.9 per 100,000 population) 
(data not shown). No outbreaks were reported for the study period.

\section{Discussion}

The results of this study demonstrate higher rates of all three infections in Vancouver Coastal Health Authority region, with a higher male-to-female ratio. However IR was the highest in adult males for shigellosis and amebiasis and in children (0-9 years) for giardiasis. The higher rates in adults (for shigellosis and amebiasis) may be due in part to sexual transmission.

For shigellosis and amebiasis, a high male-to-female ratio was noted, with a higher rate of infection in males aged 20-59 years as compared to all other age-sex groups.

Additionally, for shigellosis, adult males were significantly more likely than females to acquire shigellosis locally and an excess of shigellosis cases in adult males was observed in Vancouver health services delivery area (data not shown). Furthermore, two of the four shigellosis outbreaks reported in BC affected the MSM population. In both outbreaks, no other common risk factors such as food, restaurants or travel were noted and sexual practices (oral-anal sex) were thought to be the mode of transmission. This is in contrast to giardiasis which affected males more than females across all age groups with the highest rate reported in males aged 0-9 years which is less indicative of sexual transmission.

In Canada, other outbreaks of shigellosis where sexual transmission was implicated have been reported. In 1999-2001 an outbreak of S. sonnei and S. flexneri affected the MSM population in Quebec $(24,25)$ and in July 2014, a cluster of shigellosis cases was reported among MSM in Toronto. Outbreaks of shigellosis affecting MSM populations are reported by many developed countries (26-33). In MSM populations, shigellosis is predominantly a sexually-transmitted infection (15), with the greatest risk of transmission associated with sexual practices involving direct oral-anal contact $(7,8,15,25,27,31)$. Additionally, having multiple sexual partners could be responsible for widespread dissemination of Shigella in MSM (34). Human immunodeficiency virus infection has also been identified as an important risk factor for shigellosis in MSM $(7,15,27)$.

Analysis demonstrated a shift in the dominant infecting Shigella species (Shigella sonnei to Shigella flexneri) around 2009. Wilmer et al. (20) reported similar findings in a study where Shigella flexneri became the dominant circulating strain in the MSM population within Vancouver City Centre after 2008. Others have also reported a change in the dominant Shigella species in the same MSM population $(27,35,36)$. These shifts may reflect some degree of herd immunity towards a given Shigella species (7).

This study also found that adult males were more likely than adult females to acquire shigellosis locally $(R R=1.9)$. A similar finding was reported in a shigellosis outbreak in Wales, where locally acquired shigellosis occurred predominantly in males who had reported MSM activity in the week before illness (33).
A higher risk of travel in female cases is indicative of acquiring shigellosis via risk factors considered to be more common during travel including contaminated food and water.

The highest annual average incidence for amebiasis was reported in adult males (16.7 per 100,000 population). The reasons for this are unclear. There was very little sexual exposure information on amebiasis. Entamoeba histolytica is usually transmitted from person-to-person (10) or via contaminated water (12). Since most British Columbians have access to safe drinking water (37), apart from travel to endemic countries, sexual transmission seems likely for this age-sex group. Sexual transmission of $E$. histolytica has been reported in the MSM population, with oral-anal sexual practices considered to be the mode of transmission $(16,38,39)$.

The rate of giardiasis was higher for males in all age groups, with males aged 0-9 years having the highest rate. This finding is similar to observations reported by other developed countries (40-43), where Giardia most commonly infected small children in day-care centres and transmission was associated with poor hand hygiene. Given a similar pattern of giardiasis in BC, sexual transmission of Giardia seems less likely, or may be occurring at low rates, or is being overwhelmed by other transmission routes such as contact with contaminated water, travel to endemic countries and transmission in day-cares centres (40).

While this study has demonstrated a higher incidence of some enteric infections in males aged 20-59 years, not all adult male excess disease can be attributed to sexual transmission and not all sexual transmission will be observable by an excess in adult males. The combination of adult age and male sex used to identify an at-risk population is not a specific indicator of sexual transmission. Other factors (such as contaminated water, occupational and outdoor recreational exposure) may also account for the highest incidence observed in this group. Additionally, heterosexual adults are also at risk of STEI through oral-anal contact. Missing exposure information due to the lack of case interviews, incomplete assessment of sexual risk factors or incomplete data entry further hampered the ability to attribute cases to a specific transmission route.

Despite growing literature on the risk of STEls, prevention guidelines and educational information for at-risk populations are not widely available. Public health guidelines on this topic do not appear to be available in Canada. Such guidelines could address the public health investigation required to better assess the risk of STEls and modes of transmission, the need for contact tracing and educational messaging recommended for cases, at-risk populations and the general population. The findings of this study led to a review of the provincial enteric case follow-up forms to better capture information about sexual practices that increase the risk of STEls.

A timely diagnosis and treatment of enteric infections will not only decrease the duration of illness but also interrupt its transmission (4,29). Currently, the Canadian Guidelines on Sexually Transmitted Infections recommend that health care providers test for enteric pathogens if clients report anorectal sexual activities and/or present with compatible symptoms (4). Additionally, health care providers should provide safe 
sex counseling based on a personalized sexual health risk assessment (29). Currently, intense efforts to educate the atrisk population have been reported only during STEI outbreaks $(27,44)$. However, to increase awareness about STEls among at-risk populations, sexual health promotion messaging needs to occur on a more routine basis and should include information about STEls, advice on avoiding unprotected oral-anal contact (especially if the partner is sick), hand hygiene following sexual contact and to seek medical advice for gastroenteritis $(15,31)$.

\section{Conclusion}

This study suggests that sexual transmission of enteric infections, in particular shigellosis and amebiasis, may be occurring among MSM in Vancouver, BC. This conclusion is supported by outbreak data and limited case exposure (sexual activity, travel) history. To reduce the incidence of STEls, public health interventions should expand beyond safe food and hand hygiene practices. Continued surveillance especially of case exposure history may also help to guide public health interventions to reduce STEI.

\section{Acknowledgements}

The authors thank the regional health authorities and the environmental health officers involved in the surveillance data collection and case follow-ups and the BC laboratories involved in diagnosis of cases included in the manuscript. We also wish to thank Marsha Taylor, Michael Otterstatter, Sophie Li and especially Dr. Pablo Nepomnaschy for their guidance and valuable feedback during this project.

\section{Conflict of interest}

None.

\section{Funding}

None.

\section{References}

1. Fletcher SM, Damien S, Harkness J, Ellis J. Enteric Protozoa in the developed world: A public health perspective. Clin Microbiol Rev. July 2012;25(3):420-449.

2. Public Health Agency of Canada. Overview: FoodNet Canada: Reducing the burden of gastrointestinal disease in Canada. Ottawa ON: Public Health Agency of Canada; 2013. http://www.phac-aspc.gc.ca/foodnetcanada/overviewapercu-eng.php.
3. Centers for Disease Control and Prevention (CDC). Division of Foodborne, Waterborne, and Environmental Diseases: Enteric Diseases Epidemiology Branch . Washington DC: CDC; 2013. http://www.cdc.gov/ncezid/dfwed/edeb/.

4. Public Health Agency of Canada. Canadian guidelines on sexually transmitted infections. Ottawa ON: Public Health Agency of Canada; 2013.

5. Wiwanitkit V. Sexually transmitted Shigellosis. Sex Disab. 2006;24(1).

6. Rompalo AM. Diagnosis and treatment of sexually acquired proctitis and proctocolitis: An update. Clin Infec Dis. 1998;28(Supplement 1):S84-S90 .

7. Daskalakis DC, Blaser MJ. Another perfect storm: Shigella men who have sex with men, and HIV. Clin Infec Dis. 2007;44(3):335-337.

8. Tauxe RV, Macdonald RC, Hargrett-Bean N, Blake PA. The persistence of Shigella flexneri in the United States: Increasing role of adult males. Am J Public Health. Nov 1998;78(11):1432-1435.

9. Mildvan D, Gelb AM, William D. Venereal transmission of enteric pathogens in male homosexuals: Two case reports. JAMA. 1977;238(13):1387-1389.

10. Ortega HB, Borchardt KA, Hamilton R, Ortega P, Mahood J. Enteric pathogenic protozoa in homosexual men from San Francisco. Sex Transm Dis. Apr - Jun 1984;11(2):59-63.

11. Tessier J, Gal D. Giardiasis. Prim Care Update. 1999;6(1):1-4.

12. Public Health Agency of Canada. Pathogen safety data sheet; Infectious Substances. Ottawa ON: Public Health Agency of Canada; 2011. http://www.phac-aspc.gc.ca/labbio/res/psds-ftss/index-eng.php.

13. Reller ME, Olsen SJ, Kressel AB, Moon TD, Kubota KA, Adcock MP, Mintz ED. Sexual transmission of typhoid fever: A multistate outbreak among men who have sex with men. Clin Infec Dis. 2003;37(1):141-144.

14. Quinn TC, Goodell SE, Fennell C, Wang SP, Schuffler MD, Holmes KK, Stamm WE. Infections with Campylobacter jejuni and Campylobacter-like organisms in homosexual men. Ann Intern Med. Aug 1984;101:187-192.

15. Aragón TJ, Vugia D, Shallow S, Samuel MC, Reingold A, Agngulo FJ, Bradford WZ. Case-control study of Shigellosis in San Francisco: The role of sexual transmission and HIV infection. Clin Infec Dis. 2007;44(3):327-334.

16. Stark D, Van Hal SJ, Mathews G, Harkness J, Marriott D. Invasive amebiasis in men who have sex with men, Australia. Emerg Infec Dis, Jul 2008;14(7):1141-1143.

17. DuPont HL, Levine MM, Hornick RB, Formal SB. Inoculum size in shigellosis and implications for expected mode of transmission. J Infect Dis, June 1989;159(6):1126-8.

18. Klausner J, Hook E. Current diagnosis and treatment of sexually transmitted diseases. New York: McGraw-Hill Medical; 2007. 
19. BC Centre for Disease Control. Diseases and conditions: Giardiasis overview . Vancouver BC; BCCDC; 2010. http:// www.bccdc.ca/health-info/diseases-conditions/Giardiasis.

20. Wilmer A, Romney MG, Gustafson R, Sandhu J, Chu T, Ng C, Hull MW. Shigella flexneri Serotype I in men who have sex with men in Vancouver, Canada. HIV Med. 2015;16(3):168175.

21. Strauss B, Kurzac C, Embree G, Sevigny R, Paccagnella A, Fyfe M. Clusters of Shigella sonnei in men who have sex with men, British Columbia, 2001. Can Comm Dis Rep. Jul 2001;27(13):109-10.

22. Canadian Network for Public Health Intelligence (CNPHI). Outbreak module. Ottawa ON: CNPHI; 2014. https://www. cnphi-rcrsp.ca.

23. Taylor M, MacDougall L, Li M, Galanis E, BE. The impact of international travel on the epidemiology of enteric infections, British Columbia, 2008. Can J Public Health. 2010;101(4):332-36.

24. Public Health Agency of Canada. Canadian integrated surveillance report: Salmonella, Campylobacter, verotoxigenic E. coli and Shigella, from 2000 to 2004. Can Comm Dis Rep. December 2009;35S3: 1-50.

25. Gaudreau C, Bruneau A, Ismaïl J. Outbreak of Shigella flexneri and Shigella sonnei enterocolitis in men who have sex with men, Quebec, 1999 to 2001. Can Comm Dis Rep. April 2005;31(8).

26. Morgan $O$, Crook P, Cheasty T, Jiggle B, Giraudon I, Hughes $\mathrm{H}$. Shigella sonnei outbreak among men who have sex with men - San Francisco, California, 2000-2001. MMWR. Oct 2001;50(42):922-6.

27. Morgan $O$, Crook $P$, Cheasty $T$, Jiggle B, Giraudon I, Hughes $\mathrm{H}$, Jones SM. Shigella sonnei outbreak among homosexual men, London. Emerg Infec Dis. Sept 2006;12(9):1458-1460.

28. O'Sullivan B, Valerie D, Pontivivo G, Karagiannis T, Marriott D, Harkness J. Shigellosis linked to sex venues, Australia. Emerg Infec Dis. Aug 2002;8(8):862-864.

29. Rowe SL, Radwan S, Lalor K, Valcanis M, Gregory JE. An outbreak of shigellosis among men who have sex with men, Victoria, 2008. Vic Inf Dis Bull. Dec 2010;13(4):119-121.

30. Marcus U, Zucs P, Bremer V, Osamah H. Cluster of shigellosis in men in Berlin in 2001. Euro Surveill. 2002;6(33):1862.

31. Marcus U, Zucs P, Bremer B, Hamouda O, Prager R, Tschaepe $H$, Kramer M. Shigellosis: A re-emerging sexually transmitted infection: outbreak in men having sex with men in Berlin. Int J STD AIDS. Aug 2004;15(8):533-537.
32. Okame M, Adachi E, Sato H, Shimizu S, Kikuchi T, Miyazaki N, Koga M. Shigella sonnei outbreak among men who have sex with men in Tokyo. Jpn J Infect Dis. 2012;65:277-278.

33. Borg ML, Modi A, Tostmann A., Gobin M, Cartwright J, Quigley C. Ongoing outbreak of Shigella flexneri serotype $3 a$ in men who have sex with men in England and Wales, data from 2009-2011. Euro Surveill. 2012;17(13):20137.

34. Drusin LM, Genvert G, Topf-Olstein B, Levy-Zombek E. Shigellosis. Another sexually transmitted disease? Sex Transm Infec. Oct 1976;52(5):348-350.

35. Ratnayake R, Allard R, Pilon PA. Shifting dominance of Shigella species in men who have sex with men. Epidemiol Infect. 2012;140(11):2082-2086.

36. Pro-MED mail database. Shigellosis, changing epidemiology - Canada. Brookline MA: International Society for Infectious Diseases: Feb 16 2010. http://www.promedmail.org/ post/383254.

37. Office of the Provincial Health Officer. Progress on the Action Plan for Safe Drinking Water in BC, 2011. Victoria BC: Ministry of Health; 2012. http://www.health.gov.bc.ca/pho/ pdf/drinking-water-report-2011.pdf

38. Ohnishi K, Kato Y, Imamura A, Fukayama M, Sunoda T, Sakaue Y, Sagara H. Present characteristics of symptomatic Entamoeba histolytica infection in the big cities of Japan. Epidemiol Infect. Jan 2004;132(1):57-60.

39. Zhou F, Li M, Yang Y, Gao C, Li X, Jen Q, Gao L. Seroprevalence of Entamoeba histolytica infection among Chinese men who have sex with men. Negl Trop Dis. May 2013;7(5):e2232.

40. Espelage W, Heiden MA, Stark K, Alpers K. Characteristics and risk factors for symptomatic Giardia lamblia infections in Germany. BioMed Cent Public Health. Jan 2010;10(41).

41. Gray SF, Gunnell DJ, Peters TJ. Risk factors for Giardiasis: A case-control study in Avon and Somerset. Epidemiol Infect. August 1994;113(1):95-102.

42. Laupland KB, Church DL. Population-based laboratory surveillance for Giardia sp. and Cryptosporidium sp. infections in a large Canadian health region. BioMed Cent Infect Dis. Sept 2005;5(72).

43. Yoder JS, Beach MJ. Giardiasis surveillance: United States, 2003-2005. MMWR Surveill Summ. Sept 2007;56(SS07):1118.

44. Klausner JD, Aragon T, Enanoria WT, Mann JK, Zapitz VM, Portnoy D. Shigella sonnei outbreak among men who have sex with men: San Francisco, California. 2000-2001. MMWR. 2001;50(42):922-926. 